\title{
Spatio-temporal variation and the driving forces of tea production in China over the last 30 years
}

\author{
XIAO Zhi ${ }^{1,2}$, "HUANG Xianjin ${ }^{1}$, ZANG Zheng ${ }^{1}$, "YANG Hong ${ }^{1,3}$ \\ 1. School of Geographic and Oceanographic Sciences, Nanjing University, Nanjing 210023, China; \\ 2. Kaili University, Kaili 556011, Guizhou, China; \\ 3. Department of Geography and Environmental Science, University of Reading, Reading RG6 6AB, UK
}

\begin{abstract}
As a daily necessity and an important cash crop in China and many other countries, tea has received increasing attention. Using production concentration index model and industry's barycenter theory, we analyzed the spatio-temporal distribution of tea production and barycenter movement trajectory of tea plantations and production in China between 1986 and 2015. Driving forces of the movement were also analyzed. From 1986 to 2000, tea production in China's Mainland of grew slowly (by $210 \times 10^{3} \mathrm{t}$ ). The continuous increase in tea yield per unit area was the primary contributor (more than 60\%) to the growth in tea production during this period. Since China joined the World Trade Organization (WTO) in 2001, tea production has grown rapidly, by $1.59 \times 10^{6} \mathrm{t}$ between 2001 and 2015 . The increase in the tea plantations area is the main contributor. Over the last 30 years, the barycenters of tea production in China have moved westward from the Dongting Lake Plain to the eastern fringe of the Yunnan-Guizhou Plateau. Guizhou, Guangxi, and Sichuan in southwestern China have gradually become regions of new concentrated tea plantations and main tea production provinces. Lower cost of land and labor in southwestern China are the main drivers of the westward movement of China's tea industry. In addition, supportive policies and the favorable natural geographical environment contribute to the westward movement of tea industry. Our research highlights the spatio-temporal variation of China's tea production in the last three decades. The result indicates importance to make appropriate policies to promote the development of tea industry in China.
\end{abstract}

Keywords: tea industry; spatio-temporal variation; driving force; China

\section{Introduction}

Tea is a daily necessity in China, the UK and many other countries. Tea is also an important cash crop for many farmers in the world. In some sense, tea is one of China's labels on the world stage. Tea has been planted and drunk in China for more than one thousand years.

Received: 2017-03-28 Accepted: 2017-07-05

Foundation: National Natural Science Foundation of China, No.41571162; National Social Science Foundation of China, No.17ZDA061

Author: Xiao Zhi (1974-), PhD Candidate and Associate Professor, specialized in resources geography and land use change. E-mail: zhi2008xiao@163.com

"Corresponding author: Huang Xianjin (1968-), Professor, specialized in land use change. E-mail: hxj369@nju.edu.cn or Yang Hong (1978-), lecturer, specialized in environmental science. E-mail: hongyanghy@gmail.com 
Since the reform and opening up policy in the late 1970s, China's tea production has increasingly relied on policy and new technology. As the largest tea producer, China contributed 2.278 million tons tea in 2015, accounting for $42.94 \%$ of world production (Table 1 ). The tea industry has already become an important supporting industry in some tea-production regions in China (Zhang, 2012). Tea export and income from foreign countries have promoted the economic development ( $\mathrm{Su}, 2011)$. In addition, the tea industry plays a pivotal role in upgrading agricultural structure, increasing farmers' income, and constructing sustainable rural areas (He, 2011; Wei and Li, 2014).

Table 1 World tea production from major producers (thousand tons)

\begin{tabular}{lcccccccc}
\hline \multicolumn{1}{c}{ Region } & 1985 & 1990 & 1995 & 2000 & 2005 & 2010 & 2015 \\
\hline World & $\mathbf{2 2 9 0}$ & $\mathbf{2 5 3 1}$ & $\mathbf{2 5 2 1}$ & $\mathbf{2 9 4 0}$ & $\mathbf{3 5 3 7}$ & $\mathbf{4 2 8 1}$ & $\mathbf{5 3 0 5}$ \\
China's Mainland & 432 & 540 & 588 & 683 & 935 & 1475 & 2278 \\
India & 656 & 720 & 756 & 847 & 946 & 966 & 1,209 \\
Kenya & 147 & 197 & 245 & 236 & 323 & 399 & 399 \\
Sri Lanka & 215 & 234 & 246 & 307 & 317 & 331 & 329 \\
Turkey & 137 & 127 & 103 & 170 & 222 & 231 & 259 \\
Vietnam & 31 & 40 & 40 & 59 & 133 & 175 & 170 \\
Indonesia & 132 & 145 & 144 & 163 & 156 & 151 & 129 \\
\hline
\end{tabular}

Source: International Tea Committee (ITC), Annual Bulletin of Statistics, 1993, 2001, 2007, 2016.

Researchers have studied world tea industry mainly from the perspective of industrial economics (Ganewatta et al., 2005; Gesimba et al., 2005) and management science (Blowfield, 2003; Hazarika and Subramanian, 1999; Loconto, 2014) to promote its development. In particular, China's tea production received wide attention. Some important and interesting conclusions have been reached. For example, (1) a tea farmer's years of education, the size of his/her family labor force, and the location of his/her village, along with the government's function had an insignificant impact on tea farmers' investment intentions ( $\mathrm{Su}, 2010)$; (2) innovations of technology and management played a significant role in promoting the development of China's tea industry (Niu et al., 2007); and (3) the promulgation of regulations for pesticide residues had a significant negative impact on the tea trade (Chen, 2011). These conclusions were drawn primarily based on the theories of industrial economics and management without, in most cases, considering the geographical location and spatial factors.

Since joining the World Trade Organization (WTO) in 2001, China has taken more measures to adjust the structure of the agricultural and forestry industry and to optimize the urban/rural land use. In the meantime, China's tea industry has faced a series of new challenges and opportunities, resulting in changes in China's tea production and trade. Under the circumstance, analyses of the spatio-temporal pattern of tea industry in China and its driving forces are of theoretical value and practical significance. However, most previous studies focus on tea production in the regional perspective, without consideration of the geographical location factor which also affects the development of the tea industry. In particular, due to the data limitations, it is still unclear about the spatio-temporal pattern of the tea production pattern and its driving factors in China.

Spatial analysis is a branch of geography research (Li et al., 2017; Yao et al., 2013). Re- 
searchers have explored the sequential variation process, geographical aggregation characteristics, and influencing factors of crops, including grain (Jin, 2014; Liu et al., 2013), corn (Tan et al., 2014; Yang et al., 2016), vegetables (Ji et al., 2016), soybeans (Zhang et al., 2014), and sugar (Gao et al., 2016). However, to the best of our knowledge, the understanding of the spatial pattern of China's tea production is still very limited. Using the production concentration index model and the industry's barycenter theory, the current study attempts to investigate the spatio-temporal evolutionary trend of tea production in China before and after China joined the WTO. In addition, we explored the driving forces of the evolution of tea production in China. Our results provide a valuable reference for optimizing the distribution of tea production in China.

\section{Data and methods}

\subsection{Data sources}

The research period of this paper is from 1986 to 2015. The data were obtained from the Tea Database, Ministry of Agriculture, the People's Republic of China (http://202.127.42. 157/moazzys/chaye_cx.aspx) and China Statistical Yearbook from 1986 to 2016 (http://www.stats.gov.cn/tjsj/ndsj/). The map data were obtained from the National Geomatics Center of China (NGCC, http://ngcc.sbsm.gov.cn/). The research areas are focused on 18 tea-producing regions in China's Mainland (hereinafter China for convenience), while the relevant information for Taiwan is excluded from this study due to the data limitation. According to the Economic Regionalization Scheme of the National Bureau of Statistics of China, tea production regions in China are classified into eastern, central and southwestern areas (Figure 1). Because tea is planted only in part areas of Gansu, Shaanxi, Henan, and Shandong, the geometric centers of the tea-producing region in these four provinces are considered as their barycenters. For the remaining provinces, the geometric centers of the administrative region of each province are considered as their barycenters. Considering the change in the administrative relationship between Chongqing and Sichuan, 17 tea-producing provinces, cities and autonomous regions are analyzed as the spatial units for the period before 1997 , and $\left(103.46^{\circ} \mathrm{E}\right.$, $\left.30.53^{\circ} \mathrm{N}\right)(\mathrm{X}, \mathrm{Y})$ are set as the barycenter coordinates of Sichuan before 1997. In 1997, Chongqing became a direct-controlled municipality. Therefore, $\left(102.73^{\circ} \mathrm{E}, 30.61^{\circ} \mathrm{N}\right)$ are set as the barycenter coordinates of Sichuan after 1997.

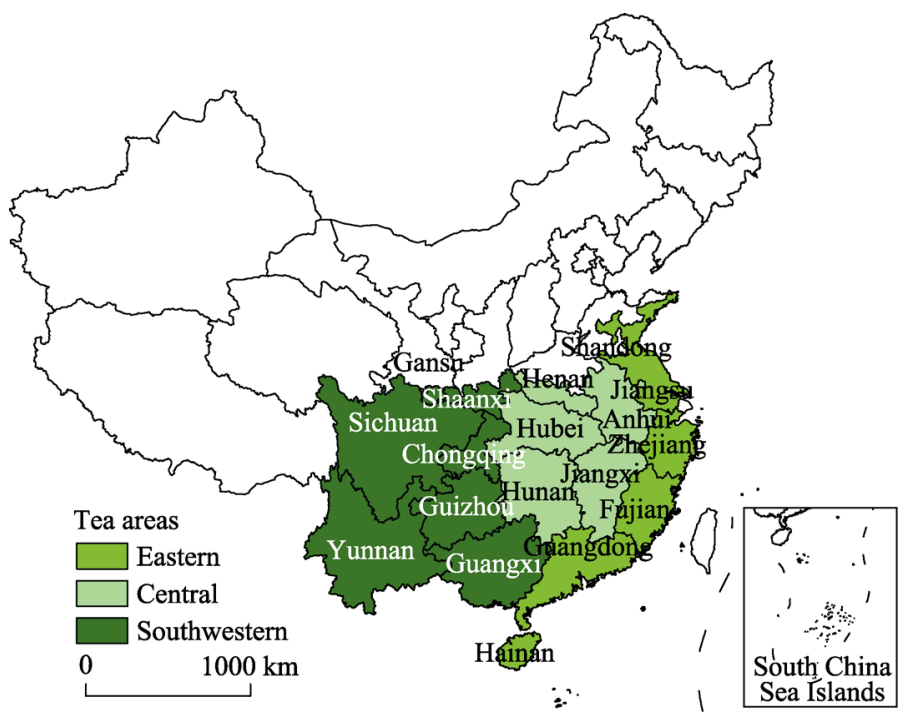

Figure 1 Tea production areas in China 


\subsection{Research methods}

\subsubsection{Measuring tea production rates}

Based on the crop yield decomposition method proposed by Zhu et al. (1997), the increase in tea production can be decomposed into three terms: the increment product in the tea plantation area and the past tea yield, the increment product in tea yield and the past area, and the increment product in the tea plantation area and the increment in tea yield. Given this decomposition, the rates of contribution (percentage) of the increment in the tea plantation area and the increment in tea yield to the increase in tea production quantity were calculated as follows (Zhu et al., 1997):

$$
\begin{aligned}
& d A=\left(A_{2}-A_{1}\right) * 1 / 2 *\left(Y_{2}-Y_{1}\right) / P * 100 \\
& d Y=\left(Y_{2}-Y_{1}\right) * 1 / 2 *\left(A_{2}+A_{1}\right) / P * 100
\end{aligned}
$$

where $\mathrm{dA}$ and $\mathrm{dY}$ represent the rates of contribution of the increment in the tea plantation area and the increment in tea yield to tea production quantity, respectively; P represents the difference in tea production quantity between the comparison year and the base year; $A_{1}$ and $Y_{1}$ represent the tea production area and the tea yield in the base year; and $A_{2}$ and $Y_{2}$ represent the tea production area and the tea yield in the comparison year.

\subsubsection{Production concentration index (PCI)}

The PCI refers to the proportion of tea production in a region (the area of tea plantations in the region) in terms of the total tea production of the entire country (the total area of tea plantations in the country) during a given period. The PCI is commonly used to estimate the spatial concentration of an industry and is calculated using the following equation (Song and Zhang, 2005):

$$
C_{i t}=M_{i t} / \sum_{i=1}^{n} M_{i t}
$$

where $C_{i t}$ represents the PCI of the tea production quantity (the area of tea plantations) in province (city or autonomous region) $i$ in China during period $t$; $M_{i t}$ represents the tea production quantity (the area of tea plantations) in province (city or autonomous region) $i$ during period $t$; and $n$ represents the total number of tea-producing provinces in China. The contribution of the tea production quantity (the area of tea plantation) in a region at a certain time to the tea production quantity (the area of tea plantation) of the entire country can be determined by calculating the PCI. In addition, the time series change in the PCI can reflect the change in the standing of a region in the entire country in terms of tea production. Therefore, the PCI can be used to horizontally and longitudinally analyze the variation in the regional pattern of tea production in China.

\subsubsection{Industry's barycenter theory}

The barycenter of an industry is the barycenter of the spatial distribution of this industry in the region (Amos, 1988). Due to the different economic development rates inside the region, the barycenter of the industrial development changes constantly (Li et al., 2012). Therefore, the analysis of the location and the movement path of the barycenter of an industry is the research focus of the spatial distribution of the industry (Bai, 2015).

(1) Location of the barycenter

The location of the barycenter was calculated as follows (Zhang and $\mathrm{Gu}, 2002$ ): 


$$
X=\sum_{i=1}^{n} M_{i} X_{i} / \sum_{i=1}^{n} M_{i}, Y=\sum_{i=1}^{n} M_{i} Y_{i} / \sum_{i=1}^{n} M_{i}
$$

where $X$ and $Y$ represent the geometric spatial center (barycenter) of the certain attribute of the tea industry in the region; $X_{i}$ and $Y_{i}$ represent the coordinates of the geographical center of subregion $i$; $n$ represents the total number of administrative sub-regions; and $M_{i}$ represents the numerical value of a certain attribute (e.g., crop area, crop yield) of the tea industry in sub-region $i$.

(2) Movement distance of the barycenter

The inter-annual spatial distance of the barycenter movement was calculated using the following equation (Sun and Zhang, 2012):

$$
D_{i-j}=R * \sqrt{\left(X_{t}-X_{j}\right)^{2}+\left(Y_{i}-Y_{j}\right)^{2}}(i>j)
$$

where $D_{i-j}$ represents the distance over which the barycenter moves between the $j$ th year and the $i$ th year $(\mathrm{km}) ;\left(X_{i}, Y_{i}\right)$ and $\left(X_{j}, Y_{j}\right)$ represent the geographical coordinates of the barycenter in the $j$ th year and the $i$ th year; and $R$ represents the transformation coefficient of the coordinates of latitude and longitude on the earth spherical surface into a planar distance and $R$ is 111.13 in the current study.

\subsubsection{Partial least squares model (PLS)}

The PLS model is a new and improved method of multivariate statistical analysis based on the ordinary least squares model; and it can be employed to effectively decompose and screen system information (Nitzl, 2016). Therefore, the PLS model is suitable for the regression modeling of multiple independent variables into dependent variables and demonstrates a higher reliability when there is multi-collinearity among the variables.

In the current study, the PLS model was employed to analyze the factors affecting the spatio-temporal pattern of China's tea industry. Tea production is a process affected by both natural and social-economic factors. The primary factors affecting the tea industry mainly include natural resource endowments, industrial policies, production technologies, labor costs, and land costs (Jiang et al., 2009; Li, 2010; Li et al., 2014; Zhang et al., 2006). In the analyses, the dependent variables include the proportion of the tea plantation area in each main tea-producing region in terms of the total tea plantations area in China (Y1) and the proportion of the tea yield in each tea-producing region in terms of the average tea yield in China (Y2) during the research period. Referring previous researches (Li, 2010; Li et al., 2014; Jiang et al., 2009; Wan, 2016; Zhang et al., 2006), the following variables were selected as independent variables: the proportion of tea plantation area in terms of the total plantation area (X1), the proportion of expenditures on the agricultural and forestry industry in terms of the general public budget revenue (X2), the proportion of turnover on the technical market in terms of gross domestic product (GDP) (X3), the ratio of the per capita income of rural residents to per capita income of urban residents (X4), and the proportion of the land value-added tax revenue in terms of the total value-added tax revenue(X5). The analyses were conducted using the software SIMCA-P11.5 (Umetrics, Umeà, Sweden) (Nitzl, 2016; Zang et al., 2017).

\section{Results}

\subsection{Trend analysis and contribution analysis}

In this study, trends of total tea plantation, production, and yield over the last 30 years were 
analyzed. In addition, the contribution factors of tea plantation area and tea yield to total tea production in China were explored.

\subsubsection{Trend analysis}

Overall, the tea plantation area in China increased from 1986 to 2015 (Figure 2). The expansion of tea plantations can be approximately divided into two periods by the year 2001: the slow growth period (1986-2001) and the rapid growth period (2001-2015). During the first period, the tea plantation area in China increased by only 70 thousand ha and even decreased slightly in several years. After 2001, tea plantation area grew rapidly, at an average annual rate of $7.11 \%$.

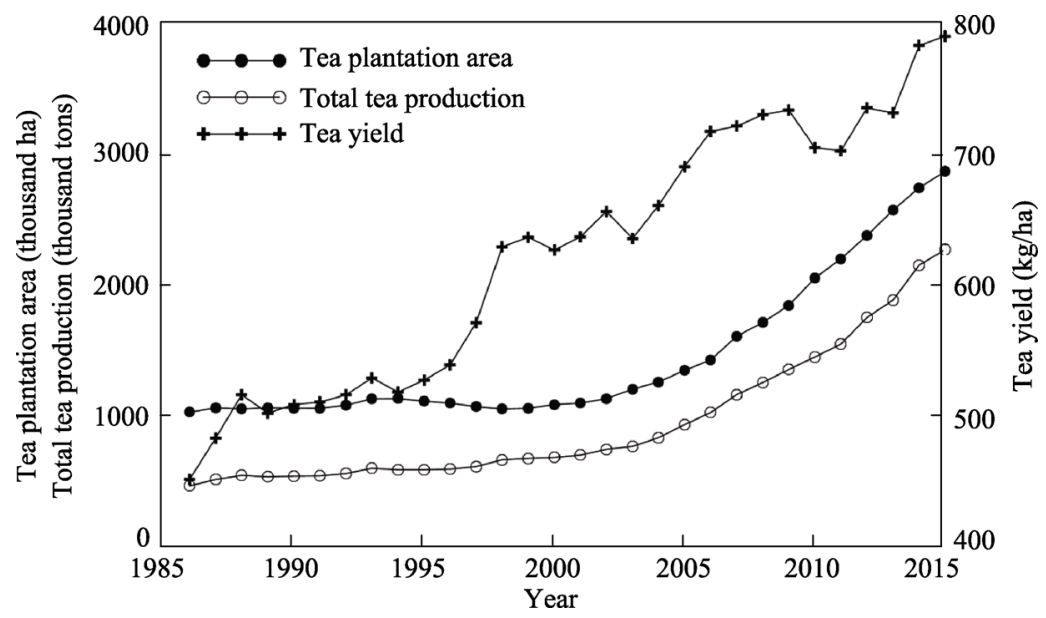

Figure 2 Tea plantation area (thousands ha), total tea production (thousands tons), and tea yield ( $\mathrm{kg} / \mathrm{ha}$ ) in China between 1986 and 2015

Tea yield fluctuated over the last 30 years, reaching a minimum $(452 \mathrm{~kg} / \mathrm{ha})$ and a maximum (794 kg/ha) in 1986 and 2015, respectively. Although China's tea yield has exhibited an increasing trend, it remains considerably less than the world average yield. For example, according to International Tea Committee's Annual Bulletin of Statistics 2016, the tea yield in China was only $67.11 \%$ of the world average tea yield (3-year average) between 2013 and 2015.

With the combined effects of the two factors noted above, total tea production in China exhibited a continuously increasing trend in the last three decades. Before 2001, tea production increased slowly from 470 thousand tons in 1986 to 680 thousand tons in 2000, a mere increase of 210 thousand tons. From 2001, total tea production has grown increasingly. Notably, after the tea export quota was abolished in 2006 (Li and Liu, 2011), total tea production increased at an average annual rate of $9.24 \%$. In 2015 , total tea production in China reached 2278 thousand tons. Total tea production in China increased 1590 thousand tons between 2001 and 2015, 7.6 times of the increase between 1986 and 2000 .

\subsubsection{Contribution analysis}

The contributions of the change in the tea plantation area and tea yield to total tea production in China were calculated using Equations (1) and (2) and results are shown in Figure 3.

The increase in total tea production is mainly attributed to the increased tea yield and its contribution was higher than $60 \%$ before 2001 . The contribution of the increase in the tea yield peaked (98.27\%) in 1998. Over the same period, the contribution of the increase in the 


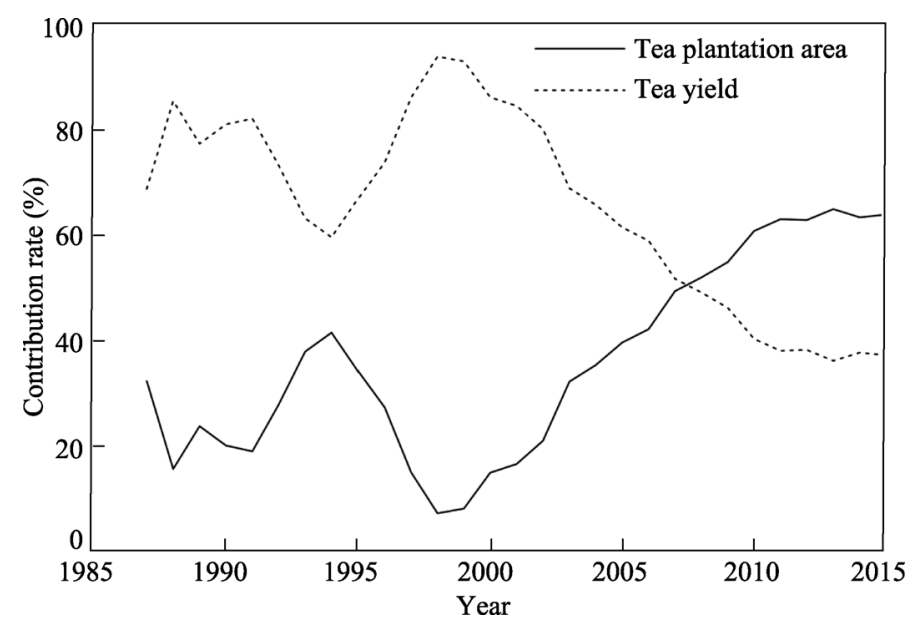

Figure 3 Contribution of the increase in the tea plantation area and the tea yield to the increase in total tea production in China from 1986 to 2015 (the year 1986 is the base year)

tea plantation area to total tea production was relatively lower, less than $40 \%$. From 2001 , total tea production increased rapidly, while the contribution of the increase in tea yield decreased markedly. During this period, the tea plantation area in China increased rapidly, and the contribution of the increase in plantation area to the increase in total tea production also increased rapidly, surpassing the contribution of the increase in tea yield in 2008. During the "12th Five-Year Plan" (2011-2015), the contribution of the increase in tea plantation area to the increase in total tea production remained greater than $60 \%$.

\subsection{Spatial analysis}

To further investigate the spatial pattern of tea production in China, 1990, 1995, 2000, 2005, 2010, and 2015 were selected as representative years. Based on the PCI of each tea-producing region (Figures 4 and 5) and the trajectory of the barycenter movement of tea production (Figure 6), the change of the spatial distribution of China's tea production was analyzed.

\subsubsection{The change of spatial distribution}

Tea plantation area is one of the main factors affecting the total tea production. The change in the distribution of tea plantations reflects the spatial movement of China's tea industry.

The PCI of tea plantations in eastern China decreased, whereas the PCI of tea plantations in southwestern China increased (Figure 4). Specifically, the PCI of tea plantations in the coastal regions of eastern China, such as Shandong, Jiangsu, and Hainan, stabilized in the range of $0-2$ during all periods. In comparison, tea plantation area in the traditional tea-producing regions, such as Zhejiang and Fujian, increased slightly, and the PCI of tea plantations in these regions decreased gradually from over 12 (1990) to below 10 (2010). The PCI of tea plantation area in Hunan, Anhui, and Jiangxi (in central China) decreased. In comparison, the tea industry was developed vigorously in Guizhou and Sichuan (in southwestern China) and in Hubei and Henan (in central China). The tea plantation area in these regions increased markedly, and these regions gradually became the new areas of concentrated tea plantation. 

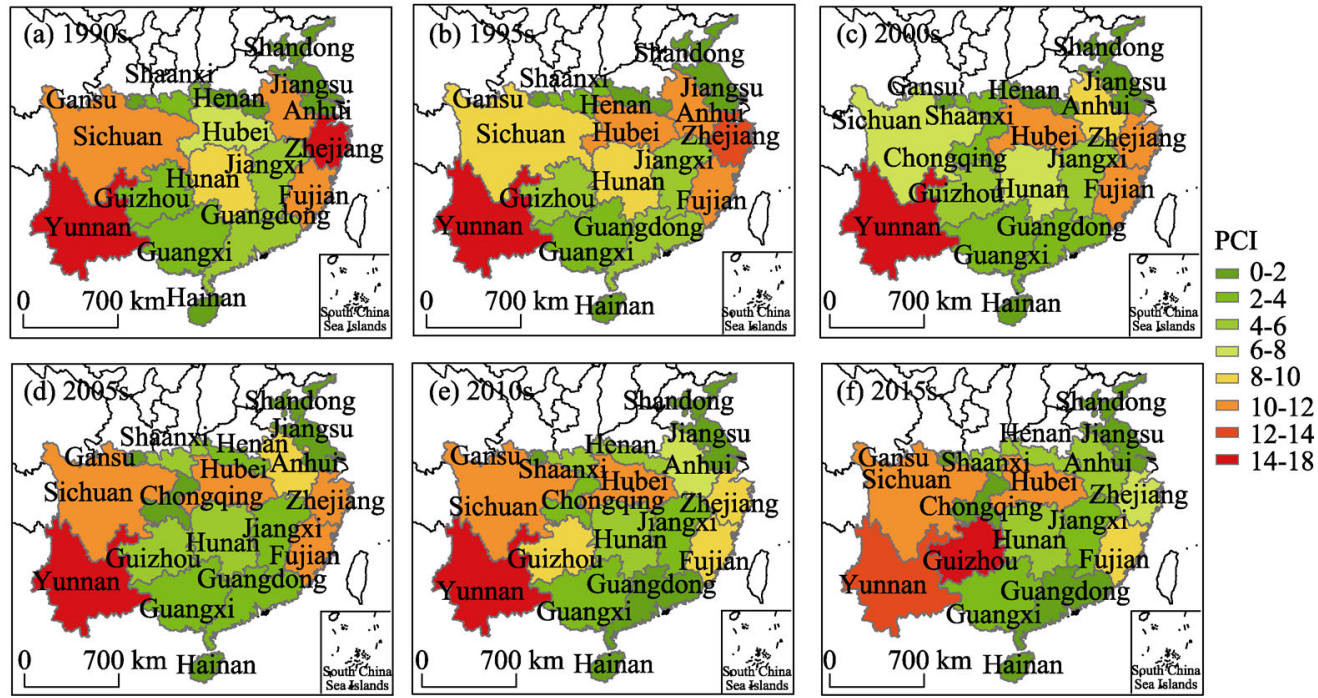

Figure 4 Spatial variation in the production concentration index (PCI) of tea plantation area in provinces in China in 1990 (a), 1995 (b), 2000 (c), 2005 (d), 2010 (e), and 2015 (f)

Figure 5 shows that the spatial pattern of the total tea production in provinces changed significantly. The proportion of tea production in Fujian (in eastern China), Hubei (in central China), and Yunnan and Guizhou (in southwestern China) in terms of China's total tea production increased markedly, by $7.18 \%, 3.71 \%, 8.58 \%$, and $7.20 \%$, respectively. The proportion of tea production in Henan (in central China) and Shaanxi (in western China) in terms of China's tea production also increased obviously, by $2.06 \%$ and $2.59 \%$, respectively. However, the proportion of the tea production in Zhejiang (in eastern China) and Hunan and Anhui (in central China) in terms of China's total tea production decreased considerably, by $14.69 \%, 8.14 \%$, and $5.12 \%$, respectively. The proportion of tea production in Jiangsu, Jiangxi, Guangdong, and Hainan in terms of China's tea production also decreased to
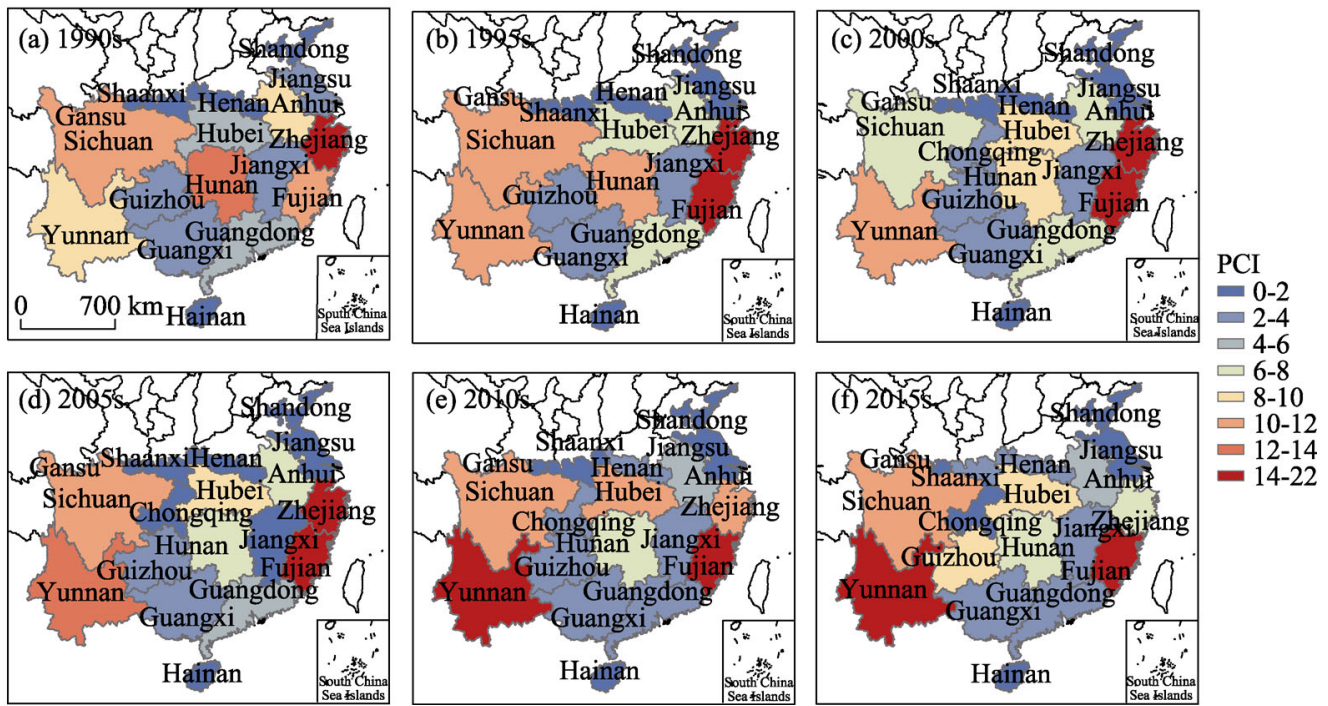

Figure 5 Spatial variation in the production concentration index (PCI) of the total tea production in provinces in China in 1990 (a), 1995 (b), 2000 (c), 2005 (d), 2010 (e) and 2015 (f) 
varying extents. Notably, in spite of the decreased proportion of the tea production in terms of China's total tea production, Zhejiang and Hunan ranked the 6th and 7th in terms of tea production in 2015. Overall, the standing of the traditional tea-producing regions in central and eastern China, such as Hunan, Anhui, Zhejiang, and Guangdong, gradually declined. The standing of Guizhou (in southwestern China) and Hubei (in central China) continuously increased and these two provinces, together with such traditional tea-producing regions as Fujian, Sichuan, and Yunnan, gradually became the main tea-producing regions in China.

\subsubsection{Change of barycenter}

The barycenters of the tea plantation areas and total tea production in China remained on the east of the base point of the regional barycenter (Jishou City), while they moved from the Dongting Lake Plain (east of $112^{\circ} 46^{\prime} \mathrm{E}$ ) to the Yunnan-Guizhou Plateau (west of $110^{\circ} 15^{\prime} \mathrm{E}$ ). By 2015, they had moved westward to the Xiangxi Autonomous Prefecture and Huaihua City near the edge of the Yunnan-Guizhou Plateau (Figure 6).

From 1986 to 1990, the barycenter of the tea plantation area shifted $75 \mathrm{~km}$ to the southwest. During the periods of 1991-2000, 2001-2010 and 2010-2015, the barycenter of the tea plantation area shifted to the northwest, with the distance of $33 \mathrm{~km}, 168 \mathrm{~km}$, and $25 \mathrm{~km}$, respectively. Overall, from 1986 to 2015, the barycenters of the tea plantation shifted $291 \mathrm{~km}$ to northwest from Ningxiang County to Guzhang County, Hunan Province. It moved $36 \mathrm{~km}$ vertically (to the north) and $278 \mathrm{~km}$ horizontally (to the west).

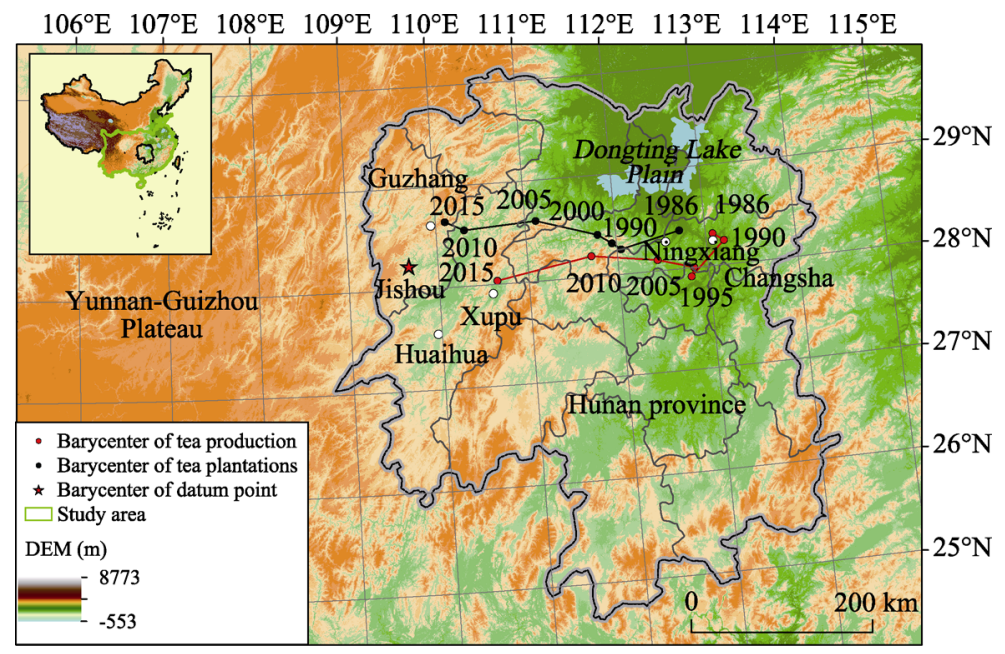

Figure 6 The movement of the barycenters of the tea plantation area and total tea production in China from 1986 to 2015

In 1986, the barycenter of total tea production was located in the north of Changsha city, Hunan Province. From 1986 to 1990, it shifted $16 \mathrm{~km}$ to the southeast; from 1991 to 1995, it shifted $57 \mathrm{~km}$ to the southwest; from 1996 to 2000 , it shifted $10 \mathrm{~km}$ to the northeast; and from 2011 to 2015, it shifted $120 \mathrm{~km}$ to the southwest (Table 2). Overall, from 1986 to 2015, the barycenter of tea production shifted $272 \mathrm{~km}$ to the southwest, moving $29 \mathrm{~km}$ vertically (south) and $290 \mathrm{~km}$ horizontally (west).

In terms of the movement rate, the barycenter of the tea plantation area moved westward at an average rate of $9.69 \mathrm{~km} \mathrm{yr}^{-1}$, higher than that of the barycenter of tea production of 
Table 2 Changes in the barycenters of the tea plantation area and total tea production in China from 1986 to 2015

\begin{tabular}{|c|c|c|c|c|c|c|}
\hline \multirow[t]{2}{*}{ Stage } & \multirow[t]{2}{*}{ Year } & \multirow[t]{2}{*}{ Period } & \multicolumn{2}{|c|}{$\begin{array}{l}\text { Shift of tea plantation } \\
\text { barycenter }\end{array}$} & \multicolumn{2}{|c|}{$\begin{array}{l}\text { Shift of total tea production } \\
\text { barycenter }\end{array}$} \\
\hline & & & Distance $(\mathrm{km})$ & Speed $\left(\mathrm{km} \mathrm{yr}^{-1}\right)$ & Distance $(\mathrm{km})$ & Speed $\left(\mathrm{km} \mathrm{yr}^{-1}\right)$ \\
\hline \multirow{3}{*}{$\begin{array}{l}\text { Before } \\
2001\end{array}$} & 1986-1990 & 7th Five-Year & 75 & 15 & 16 & 3 \\
\hline & 1991-1995 & 8th Five-Year & 13 & 3 & 57 & 11 \\
\hline & 1996-2000 & 9th Five-Year & 20 & 4 & 10 & 2 \\
\hline \multirow[t]{3}{*}{ After 2001} & 2001-2005 & 10th Five-Year & 78 & 16 & 46 & 9 \\
\hline & 2006-2010 & 11th Five-Year & 90 & 18 & 82 & 16 \\
\hline & 2011-2015 & 12th Five-Year & 25 & 5 & 120 & 24 \\
\hline
\end{tabular}

$9.06 \mathrm{~km} \mathrm{yr}^{-1}$. In four periods (the 7th Five-Year, 9th Five-Year, 10th Five-Year, and 11th Five-Year), the annual movement rate of the barycenter of tea plantation area was rapid. In general, over the 7th Five-Year and 9th Five-Year plan periods, the barycenter of total tea production moved slightly east, indicating that the regional fluctuation of tea production was much greater than that of the tea plantation area and that the tea plantation area and its movement became more stable.

\subsection{Driving factor analysis}

\subsubsection{Regression analyses}

Regression analyses were individually performed based on the tea plantations area and tea yield per unit area in the eastern, central and southwestern China. The results are shown in Table 3 and Figure 7.

Table 3 Regression coefficient of the PLS model for the tea producing regions in eastern, central, and southwestern China

\begin{tabular}{|c|c|c|c|c|c|c|}
\hline \multirow{2}{*}{ Variable } & \multicolumn{3}{|c|}{ Tea plantation area } & \multicolumn{3}{|c|}{ Tea yield } \\
\hline & Eastern & Central & Southwestern & Eastern & Central & Southwestern \\
\hline $\mathrm{X} 1$ & 0.0602 & -0.2739 & 0.2141 & 0.2481 & -0.2946 & 0.1843 \\
\hline $\mathrm{X} 2$ & 0.2832 & 0.2646 & 0.2609 & 0.3553 & 0.2841 & 0.2298 \\
\hline $\mathrm{X} 3$ & 0.2092 & 0.1222 & 0.1935 & -0.006 & 0.0875 & 0.2324 \\
\hline $\mathrm{X} 4$ & 0.4291 & 0.2386 & 0.2401 & 0.2048 & 0.2128 & 0.2701 \\
\hline $\mathrm{X} 5$ & 0.5053 & 0.3352 & 0.3096 & 0.4223 & 0.3325 & 0.3011 \\
\hline
\end{tabular}
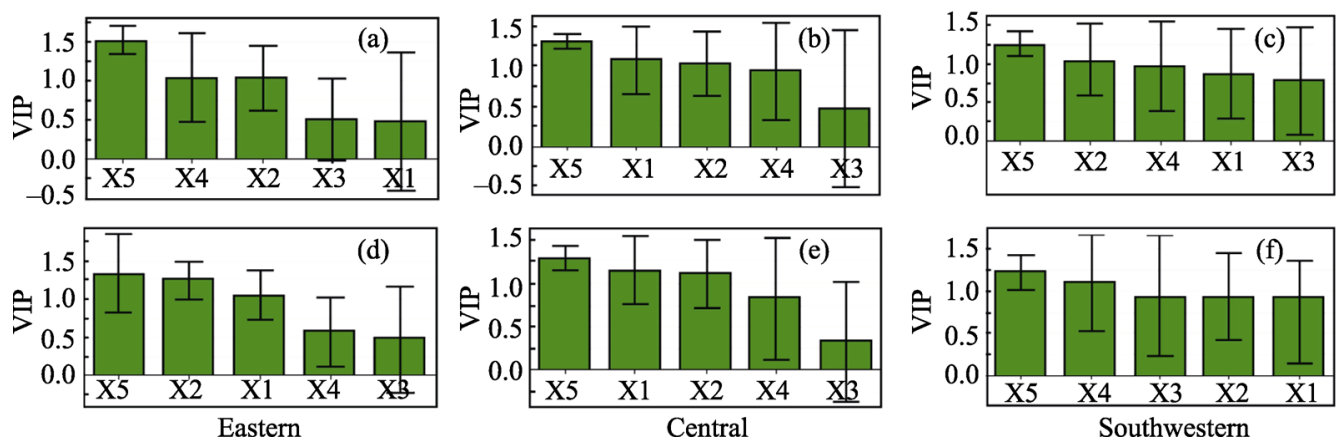

Figure 7 Variable importance projection (VIP) of five independent variables (X1-X5) of the PLS model in eastern, central, and southwestern China 
Table 3 shows the driving (positive regression coefficient) and restricting (negative regression coefficient) effects of the independent variables X1-X5 on the change in tea plantation area in different regions in China. Overall, the independent factors X1-X5 are positively correlated with the tea plantation area and the tea yield, indicating that a favorable natural environment, industry-supporting policies, the application of new technologies, and labor/land costs all promote the development of the tea industry in China.

Figure 7 demonstrates the values of the variable importance projection (VIP) in the PLS model. VIP characterizes the explanatory power of an independent variable for the dependent variable. An independent variable with a VIP value greater than 1 is often considered as the dominant factor causing changes of the dependent variable (Zang et al., 2017). As demonstrated in Figure 7, all the factors except for X3 have relatively high explanatory power for the increases in the scale of tea plantations and tea yield per unit area.

\subsubsection{Factor analysis}

(1) Land and labor costs

In terms of the importance of the five factors, regardless of the increase in the tea plantation area (Figures 7a-7c) and tea yield (Figures 7d-7f), X5, which represents land costs, exerts the most significant impact (VIP $>1$ ) on the development of the tea industry in eastern, central, and southwestern China.

In addition, X4, which represents labor costs, is positively correlated with the scale of tea plantations (eastern China) and the tea yield per unit area (southwestern China) (Figures 7a and $7 \mathrm{f}$ ), indicating that $\mathrm{X} 4$ is an important driver of the tea industrial development in some areas (VIP>1).

(2) Industry-supporting policies

As demonstrated in Figures 7c and 7d, X2, the supporting policies, has a substantial driving action on the expansion of the scale of tea plantations (southwestern China) and the increase in the tea yield per unit area (eastern China) (VIP $>1$ ).

(3) Natural environment

The proportion of the area for tea plantations (X1) represents the natural conditions suitable for developing the tea industry. As demonstrated in Figures $7 \mathrm{~b}$ and $7 \mathrm{e}, \mathrm{X} 1$ has relatively high explanatory power for the expansion of the scale of tea plantations and the increase in the tea yield per unit area in central China (VIP $>1$ ). Therefore, $\mathrm{X} 1$ has an important driving action in the central area.

\section{Discussion}

Tea industry is important in many countries, especially in China. Tea industry is closely related to many industries (He, 2011; Zhang, 2012) and is a powerful driver for economic development in the country (Wei and Li 2014). In this study, we analyzed the spatio-temporal pattern of China's tea industry and explored the factors affecting the changes.

\subsection{Costs of land and labor resources}

Our results showed a clear westward movement of China's tea industry. The westward movement of the barycenter of the distribution of tea production in China is favorable to the construction of an ecological civilization in the ecologically vulnerable and environmentally 
sensitive areas in southwestern China (Hu and Yang, 2016).

Tea production is a labor-intensive industry (Wang and Zhai, 1993). A tremendous amount of labor resource is required, from the planting of tea trees to the management of tea plantations to the picking, processing, and selling of tea leaves. Because of its relatively abundant and low-cost labor resources in southwest China, the costs of tea cultivation and processing in southwestern China are relatively smaller compared to economically developed eastern China (Li, 2010).

Tea plantation area determines the supply scale of tea production. The increase in the tea plantation area requires the input of more land resource. There are a large proportion of hills and mountains in southwestern China. Consequently, the land costs for tea plantations in southwestern China are much lower, reducing the tea production cost and providing favorable conditions to compete in tea production on the domestic and international markets.

The westward movement of the tea industry from eastern China can benefit from the relatively lower land and labor costs in southwestern China (Li, 2010), promoting the sustainable ecological development and environmental protection (Yang, 2014). Amid the westward movement of the tea industry, decision-makers in southwestern China should formulate reasonable plans for further developing the tea industry and transforming southwestern China to one of China's main tea-producing regions, characterized by large-scale, mechanized, and standardized development (Liu et al., 2014; Yang et al., 2013a). Effective measures are also needed to minimize the impact of tea industry on precious water and soil resource in Southwest China (Yang et al., 2013b; Yang, 2016).

\subsection{Supporting industrial policy}

Industrial policy is one of the important means to actively intervene the economic development (Liu, 2014). The agricultural structure adjustment strategy and the national subsidy policy for the tea industry vary among regions and consequently have an important impact on the change in the regional pattern of tea production.

Since China joined the WTO in 2001, the area of tea plantations in China has entered a rapid growth period (increasing at an annual rate of $7.11 \%$ ). The increase in the trade demand is the external cause of the increase in the area of tea plantations. In addition, the central government also attaches great importance to the development of the tea industry and provides strong support for the development of the tea industry through favorable industrial policies. These are the internal driving forces for the increase in the area of tea plantations. For example, Anhui introduced the Planning for the Development of the Tea Industry in Anhui (2003-2007) in 2003. Subsequently, the Ministry of Agriculture of China published the Planning for the Development of Key Tea-Producing Regions in China (2009-2015) in 2009. The central government has been gradually increasing the intensity of investment of special funds for the tea industry. Local governments have also prioritized tea production, processing, and logistics projects in the area of land use. The aforementioned actions, together with the implementation of various preferential tax policies, have resulted in the construction of a number of new standardized, large-scale tea plantation bases in various regions and promoted the rapid increase in the tea plantation area and the adjustment/upgrading of the tea industrial structure. 


\subsection{Natural environment}

Tea quality varies with the natural geographical environment where it grows. China's tea-producing regions are mostly located in the subtropical monsoon climate zone with hot, wet, and rainy summers. In addition, China also covers a vast area with various terrains. As a result, numerous microclimatic environments suitable for the growth of tea trees are formed (Wang and Zhai, 1993).

The natural environment in southwestern China has promoted the western movement of China's tea industry. For example, Sichuan is located in the Sichuan Basin, which has abundant precipitation, plentiful clouds, low sunshine conditions, and high relative humidity. Therefore, Sichuan has favorable natural conditions for developing its tea industry. Relying on its low-latitude, high-altitude, low-sunshine, and cloudy geographical environment, Guizhou has become a main green-tea-producing region in China (Hu and Yang, 2016). The aforementioned conditions lay a good foundation for the westward movement of the tea industry in China. In comparison, the proportion of the area of tea plantations in Shandong, Guangdong, and Hainan (in eastern China) and in Hubei and Hunan (in central China) is relatively low, limiting the increase in the area of tea plantations.

\subsection{International trade and domestic consumption}

China was once world's largest tea exporter. The gap in tea exports is narrowing between China and some member states of the Commonwealth of Nations, such as Sri Lanka and India. According to data of China's tea imports and exports since 2001 and statistics published by relevant agencies (e.g., Department of Foreign Trade, Ministry of Commerce of China, 2015), China's tea exports increased from 255,000 t in 2001 to 329,000 $\mathrm{t}$ in 2015, with an annual average growth rate of only $0.47 \%$. Therefore, foreign demand has made little contribution to the development of China's tea industry. Worse, global economic crisis, for example financial crises in 2008, can exacerbate the negative effect of international trade and China's export, including tea (Lu et al., 2015; Wu et al., 2015).

According to data provided by China Tea Marketing Association, China's domestic tea consumption increased from 206,000 $\mathrm{t}$ in 2001 to 2,050,000 $\mathrm{t}$ in 2005. Due to lack of detailed statistical data, domestic demand was excluded as an influencing factor in our analysis. However, with an average annual growth rate of $12.29 \%$, the driving action of domestic demand on the expansion of the tea plantations area and the increase in tea yield per unit area cannot be overlooked. It seems that domestic demand makes a more important contribution to the development of China's tea industry than foreign trade.

\subsection{Innovations of technology and management}

The application of new technologies can increase both tea yield and tea plantation area, which has been manifested in eastern, central, and southwestern China. Since 2000, total tea production in China has entered a period of rapid growth, at an average annual rate of $10 \%$, mainly due to the rapid increase in the proportion of the tea plantation area in the newly established tea-producing regions where improved varieties of clonal tea were planted (Xiao et $a l ., 2017$ ). For example, the area proportion of clonal tea trees in Zhejiang reached $70.80 \%$ in 2013 (Liang and Shi, 2015).

In addition, new technologies can promote the updating of the tea plantation management. 
For example, in 2005, the Ministry of Agriculture of China introduced a series of supporting policies for establishing standardized tea plantations, requiring each main tea-producing region to construct and manage new tea plantations that meet the "ecologicalization, improved variety, normalization, and standardization" requirements; certify pollution-free, organic tea production bases. A series of standardized production technologies were increasingly used, for example, the formulated fertilization based on soil testing, disease and pest prevention and control, and the mechanized picking of tea leaves (Han et al., 2016). These policies and measures have promoted obviously the increases in the tea yield and total tea production.

\subsection{Limitation and future research}

Same as many studies, several uncertainties remain in the current studies. Due to data limitation, our analysis was performed based on provincial level. Because of relatively low spatial resolution, some results may be insufficiently accurate. Similarly, because of insufficient data, only five aforementioned independent variables were used in this study to investigate the factors that drive the spatial evolution of tea production in China. The representativeness of these indices may be limited to some extent. For example, factors such as foreign trade, domestic demand and the popularization and application of new technologies can also to a certain extent affect the development of the tea industry. Tea was an important trade product on the ancient Silk Road. With the comprehensive integration and rapid development of a global economy and culture, particularly in the background of "the Belt and Road Initiatives" developed by China's government, the global tea industry will face new opportunities and challenges. The dominant factor affecting the development of tea industry may vary among regions in next decades. Therefore, future research with more accurate data will clearly increase the understanding of the development of China's tea industry.

\section{Conclusions}

Based on models for measuring production rate, the PCI and barycenter, this study analyzed the regional distribution pattern and the path of the barycenter movement of China's tea plantation area and tea production between 1986 and 2015. The driving forces of the movement of the tea industry were also analyzed. The following conclusions are obtained:

(1) The change of the tea plantations area and tea production in China can be divided into two stages by the year 2001, when China joined the WTO. In the first stage, a slow growth stage between 1986 and 2001, the increase in tea yield per unit area was the primary contributor to the growth in China's total tea production $\left(210 \times 10^{3} \mathrm{t}\right)$. In the second stage, a rapid growth stage between 2001 and 2015 , growth in total tea production $\left(1.59 \times 10^{6} \mathrm{t}\right)$ resulted primarily from an increase in the area of tea plantations. In particular, after 2011, the increase in the tea plantation area contributed steadily to more than $60 \%$ of total tea production.

(2) Over the last 30 years, there has been a clear spatial change of China's tea industry. The standings of Hunan and Anhui (in central China), as well as the traditional tea-producing regions in the eastern coastal regions of China (e.g., Zhejiang and Guangdong), have slowly declined. The tea industry has gradually moved to the southwest with advantageous natural endowments. Guizhou, Yunnan, and Sichuan, as well as Hubei, have gradually become China's main tea-producing provinces.

(3) During the last three decades, the barycenters of tea production in China have moved 
westward from the Dongting Lake Plain (east of $112^{\circ} 46^{\prime} \mathrm{E}$ ) to the eastern fringe of the Yunnan-Guizhou Plateau (west of $110^{\circ} 15^{\prime} \mathrm{E}$ ). The barycenter of the tea plantation area has moved roughly from "east-south" to "west-north". The barycenter of tea production has moved roughly from "east-north" to "west-south". In terms of the movement rate, the barycenter of the tea plantation area moved faster than the barycenter of tea production.

(4) The relatively low costs of land and labor in southwestern China lay a good foundation for the westward movement of the tea industry. In addition, the industry-supporting policies implemented by the central and local governments also ensure processes of industrial standardization, normalization and base construction. The favorable natural endowments in southwestern China have objectively encouraged China's tea industry to gradually move southwestward.

\section{References}

Amos O M, 1988. Unbalanced regional growth and regional income inequality in the latter stages of development. Regional Science and Urban Economics, 18(4): 549-566.

Bai Xue, 2015. The spatial evolution of China's economic center of gravity and the decomposition of industrial center of gravity. Inquiry into Economic Issues, (6): 18-24. (in Chinese)

Blowfield M, 2003. Ethical supply chains in the cocoa, coffee and tea industries. Greener Management International, 43(43): 14-24(11).

Chen Zongmao, 2011. Study on the problems of China's tea industry quality and safety and environmental safety. Quality and Safety of Agro-Products, (3): 5-7. (in Chinese)

Ganewatta G, Waschik R, Jayasuriya S et al., 2005. Moving up the processing ladder in primary product exports: Sri Lanka's “value-added" tea industry. Agricultural Economics, 33(3): 341-350.

Gao Qun, Zhang Youwang, Ke Yangmin, 2016. Sugar yield change and contribution factors decomposition of space and time: Based on LMDI model. Economic Geography, 36(4): 99-105. (in Chinese)

Gesimba R M, Langat M C, Liu G et al., 2005. The tea industry in Kenya: The challenges and positive developments. Journal of Applied Sciences (Pakistan), 5(2): 334-336.

Han Yu, Xiao Hongru, Song Zhiyu et al., 2016. Research on mechanization technology mode of tea plantation and management. Journal of Agricultural Science and Technology, 18(3): 74-81. (in Chinese)

Hazarika C, Subramanian S R, 1999. Estimation of technical efficiency in the stochastic frontier production function model: An application to the tea industry in Assam. Indian Journal of Agricultural Economics, 54(2): 201.

He Yanyan, 2011. The development approach of concession for bigger and stronger tea industry. Hunan Agricultural Sciences, 24(10): 21-22. (in Chinese)

Hu Jicheng, Yang Li, 2016. Review of Guizhou tea industry during the 12th Five-Year Plan period and its prospect for upcoming five-year plan. China Tea Processing, (3): 19-24. (in Chinese)

Ji Long, Li Chongguang, Zhang Shengyong, 2016. The spatial distribution of vegetable production in China and its impact on vegetable price volatility. Economic Geography, 36(1): 148-155. (in Chinese)

Jiang Hanchun, Zhao Hongying, Ge Wei, 2009. Analysis of present status and development tendency of tea industry in China. Chinese Journal of Agricultural Resources and Regional Planning, 30(3): 23-28. (in Chinese)

Jin Tao, 2014. Effects of cultivated land use on temporal-spatial variation of grain production in China. Journal of Natural Resources, 29(6): 911-919. (in Chinese)

Li Erling, Pang Anchao, Zhu Jiguang, 2012. Analysis of the evolution path and mechanism of China's agricultural agglomeration and geographic pattern. Geographical Research, 31(5): 885-898. (in Chinese)

Li Jianbao, Huang Xianjin, Yang Hong et al., 2017. Convergence of carbon intensity in the Yangtze River Delta, China. Habitat International, 60: 58-68.

Li Shirui, Wang Zhihai, Yang Zaiqiang et al., 2014. Analysis on production status of tea plant and climate characteristics in tea regions in southern Yangtze River. Journal of Arid Meteorology, 32(6): 1007-1014. (in Chinese)

Li Xilin, Liu Heguang, 2011. The development pattern and trend of the world tea trade. Agricultural Outlook, 7(4): 44-48. (in Chinese)

Li Yumei, 2010. International comparison of the relationship between land productivity and China's tea export. Journal of Agrotechnical Economics, (8): 106-116. (in Chinese)

Liang Yuerong, Shi Meng, 2015. Advances in tea plant genetics and breeding. Journal of Tea Science, 35(2): 103-109. (in Chinese) 
Liu Shejian, 2014. Evolution, questions and solutions to the industry policy. Academic Monthly, 46(2): 79-85. (in Chinese)

Liu Y, Huang X, Yang H et al., 2014. Environmental effects of land-use/cover change caused by urbanization and policies in Southwest China karst area: A case study of Guiyang. Habitat International, 44: 339-348.

Liu Zhenhuan, Li Zhengguo, Tang Pengqin et al., 2013. Change analysis of rice area and production in China during the past three decades. Journal of Geographical Sciences, 23(6): 1005-1018.

Lu Q, Yang H, Huang X et al., 2015. Multi-sectoral decomposition in decoupling industrial growth from carbon emissions in the developed Jiangsu Province, China. Energy, 82: 414-425.

Loconto A, 2014. Assembling governance: The role of standards in the Tanzanian tea industry. Journal of Cleaner Production, 107: 64-73.

Nitzl C, 2016. The use of partial least squares structural equation modeling (PLS-SEM) in management accounting research directions for future theory development. Journal of Accounting Literature, 37: 19-35.

Niu Xiaojing, Gu Gouda, Zhang Chun, 2007. World tea production and trade patterns of evolution and current situation analysis. World Agriculture, (6): 29-32. (in Chinese)

Song Jia, Zhang Yueheng, 2005. Estimation of comparative advantage of agricultural product in Pan Pearl River Delta. Research of Agricultural Modernization, 26(5): 116-120. (in Chinese)

$\mathrm{Su}$ Baocai, 2010. An empirical analysis of productive investment technical efficiency and influencing factors of tea farmers in Anxi county, Fujian Province. Issues of Forestry Economics, 30(4): 346-350. (in Chinese)

Su Zhucheng, 2011. Organization of Chinese tea industry: Performance and policy. Journal of Tea Science, 31(3): 264-272. (in Chinese)

Sun Lei, Zhang Xiaoping, 2012. Research on spatial distribution of the manufacturing in Beijing and its decomposition of center of gravity. Progress in Geography, 31(4): 491-497. (in Chinese)

Tan Jieyang, Li Zhengguo, Yang Peng et al., 2014. Spatio-temporal changes of maize sown area and yield in Northeast China between 1980 and 2010 using spatial production allocation model. Acta Geographica Sinica, 69(3): 353-364. (in Chinese)

Wan Qing, Yan Fengzhu, 2006. International competitiveness of Chinese tea industry and policy implications. Resources Science, 28(4): 118-124. (in Chinese)

Wang Yingfeng, Zhai Haiguo, 1993. A new scheme for tea ecological environment regionalization in China. Geographical Research, 12(4): 39-45. (in Chinese)

Wei Longbao, Li Jing, 2014. Analysis for effects of social capital and human capital of agricultural industry cluster on farmers' income. Issues in Agricultural Economy, 35(4): 41-47. (in Chinese)

Wu C, Huang X, Yang H et al., 2015. Embodied carbon emissions of foreign trade under the global financial crisis: A case study of Jiangsu province, China. Journal of Renewable \& Sustainable Energy, 7(4): 10288-10293.

Xiao Zhi, Huang Xianjin, Meng Hao et al., 2017. Spatial structure and evolution of tea production in China from 2009 to 2014. Geographical Research, 36(1): 109-120. (in Chinese)

Yang Hong, 2014. China must continue the momentum of green law. Nature, 509(7502): 535.

Yang Hong, 2016. China's soil plan needs strong support. Nature, 536(7617): 375.

Yang H, Flower R J, Thompson J R, 2013a. Pollution: China's new leaders offer green hope. Nature, $493(7431)$ : 163.

Yang H, Flower R J, Thompson J R, 2013b. Sustaining China's water resources. Science, 339(6116): 141.

Yang Yanzhao, Liang Yubin, Feng Zhiming et al., 2016. Temporal and spatial patterns of corn production, consumption and the balance of supply and demand in China. Research of Agricultural Modernization, 37(5): 817-823. (in Chinese)

Yao Lufeng, He Shujin, Zhao Xin, 2013. The writing of temporal and spatial variation of geography. Acta Geographica Sinica, 68(7): 1007-1011. (in Chinese)

Zang Zheng, Zou Xinqing, Song Qiaochu et al., 2017. Integrated sustainable development evaluation based on human wellbeing indices and pressure indices: A case study of the South China Sea neighboring countries. The Social Science Journal, http://dx.doi.org/10.1016/j.soscij.2017.04.007.

Zhang Chuanzheng, Zhang Ding, Li Xinghui et al., 2006. Techniques of tea counter-season production in the tea production areas of Jiangnan. Nonwood Forest Research, 24(2): 55-58. (in Chinese)

Zhang Min, Gu Chaolin, 2002. Spatial characteristics of the recent inter-provincial flow of social-economic elements in China. Geographical Research, 21(3): 313-323. (in Chinese)

Zhang Peng, 2012. Feasibility study on the development of green tea industry in southern Shaanxi. Academic Periodical of Farm Products Processing, 15(9): 108-110. (in Chinese)

Zhang Xiaofeng, Wang Hongzhi, Liu Luo et al., 2014. Spatial-temporal characteristics of soybean production potential change under the background of climate change over the past 50 years in China. Progress in Geography, 33(10): 1414-1423. (in Chinese)

Zhu Defeng, Pang Qianlin, He Xiumei, 1997. Analysis on the factors of rice yield growth in China and the countermeasures for the future development. China Rice, 3(6): 3-6. (in Chinese) 